\title{
Evapotranspiração máxima e coeficiente de cultura da berinjela cultivada em estufa plástica
}

\author{
Luis H. Loose ${ }^{1}$, Ivan C. Maldaner ${ }^{2}$, Arno B. Heldwein ${ }^{3}$, Dionéia D. P. Lucas ${ }^{4} \&$ Evandro Z. Righi $^{5}$
}

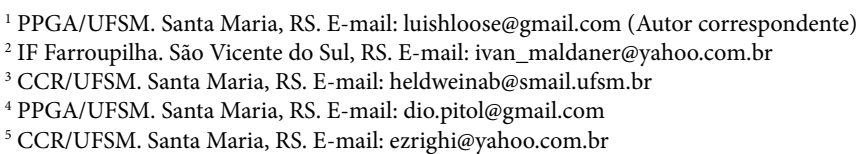

\section{Palavras-chave:}

Solanum melongena L.

demanda hídrica

cultivos protegidos

\begin{abstract}
R E S U M O
Apesar do cultivo da berinjela em estufa plástica ter aumentado no sul do Brasil, ainda é escasso o conhecimento sobre a evapotranspiração da cultura na condição de ambiente protegido para o manejo correto da irrigação. Objetivou-se determinar a evapotranspiração máxima e o coeficiente de cultura da berinjela cultivada em estufa plástica. Realizaram-se três experimentos em estufa plástica, dos quais dois na primavera dos anos de $2006 \mathrm{e}$ 2007 e o outro no outono de 2007, na condição de clima subtropical úmido de Santa Maria, RS. As plantas foram cultivadas em camalhões de solo coberto por mulching plástico e irrigado por gotejamento. A evapotranspiração máxima da cultura foi medida em seis repetições de evapotranspirômetros de drenagem, contendo $20 \mathrm{~L}$ de substrato e uma planta. A evapotranspiração de referência foi estimada pelo método de Penman-Monteith. Verificou-se que a evapotranspiração máxima da cultura foi maior na primavera do que no outono enquanto o coeficiente de cultura foi maior no outono. Conclui-se que o coeficiente de cultura da berinjela cultivada em estufa plástica pode ser estimado com boa precisão em função dos dias após o transplante ou do índice de área foliar.
\end{abstract}

\section{Key words:}

Solanum melongena L. water requirement protected cropping

\section{Maximum evapotranspiration and crop coefficient of eggplant cultivated in plastic greenhouse}

\begin{abstract}
A B S T R A C T
The eggplant cultivation in plastic greenhouse has increased in Southern Brazil. However, little is known about crop evapotranspiration in plastic greenhouse condition for proper irrigation. This study aimed to determine the maximum evapotranspiration and crop coefficient of eggplant cultivated in plastic greenhouse. Three experiments were carried out under plastic greenhouse, two in spring of 2006 and 2007 and another in fall of 2007 under the subtropical climate conditions of Santa Maria, RS. Plants were grown on ridges, covered with plastic mulching and drip irrigated. The maximum crop evapotranspiration was measured in six replications of drainage evapotranspirometer containing $20 \mathrm{~L}$ of substrate and one plant. The reference evapotranspiration was calculated by Penman-Monteith method. It was found that the maximum crop evapotranspiration in spring is greater than in fall, while the crop coefficient was greater in fall. It was concluded that crop coefficient of eggplant cultivated in plastic greenhouse can be estimated with good accuracy as a function of days after transplantating or leaf area index.
\end{abstract}

\section{INTRODUÇÃO}

A produção de hortaliças tem importante participação no PIB agrícola brasileiro e na absorção de mão-de-obra familiar. A participação da berinjela no mercado tem aumentado em razão das propriedades organolépticas, nutricionais e medicinais dos seus frutos que são excelente fonte de minerais e vitaminas (Gonçalves et al., 2006) e contribuem na redução do colesterol nos humanos (Antonini et al., 2002).

O cultivo da berinjela ocorre, preferencialmente, nas regiões e estações do ano quentes, sendo ideais temperaturas diurnas entre 25 e $35^{\circ} \mathrm{C}$ e noturnas entre 20 e $27^{\circ} \mathrm{C}$ (Ribeiro, 2007). No sul do Brasil somente partes da primavera e do verão apresentam essas condições ficando o cultivo a campo limitado às referidas épocas. Neste contexto, o cultivo em estufa plástica possibilita antecipar o transplante das mudas e estender os cultivos até o outono ampliando o período de produção e o número de cultivos por ano. Nas estufas plásticas tem-se um ganho interno de energia (Righi et al., 2002; Buriol et al., 2004; Vásquez et al., 2005), por aumentar a temperatura do ar, a soma térmica e a proteção, contra temperaturas baixas. Também é possível racionalizar o uso de fertilizantes, água e defensivos e obter hortaliças com maior qualidade também na entressafra, além de melhores preços na comercialização.

A alteração dos elementos meteorológicos pela cobertura plástica e o manejo das aberturas da estufa (Dalmago et al., 
2006), diminuem a evapotranspiração máxima da cultura (ETm) em relação ao ambiente externo. Esta redução também decorre do uso de irrigação localizada sob mulching plástico opaco sobre o solo cultivado restringindo a evaporação (Ferreira et al., 2006). Portanto, a quantificação das exigências hídricas da cultura de berinjela em estufa através da ETm é essencial por não ser possível utilizar os parâmetros dimensionados para as condições externas. Neste ambiente modificado a ETm é diferente do ambiente externo e toda a água necessária ao cultivo é fornecida por irrigação sendo a determinação precisa do coeficiente de cultura $(\mathrm{Kc})$ e da ETm imprescindível ao manejo adequado da irrigação (Fernández et al., 2010). O conhecimento do suprimento próprio de água por irrigação é fundamental para se obter alta produtividade e qualidade dos frutos (Karam et al., 2011), por ser a berinjela uma cultura sensível ao déficit e excesso hídricos, principalmente na fase de formação e colheita dos frutos (Bilibio et al., 2010).

A determinação da ETm pode ser feita a partir de modelos matemáticos que incluem variáveis meteorológicas internas ou externas à estufa e referentes às plantas. Para condições de clima subtropical úmido há estudos com essa abordagem para o pimentão (Dalmago et al., 2006; Tazzo et al., 2012), tomateiro (Valandro et al., 2007; Pivetta et al., 2011) e abóbora italiana (Heldwein et al., 2004). A ETm também pode ser determinada pela multiplicação do Kc para cada subperíodo de desenvolvimento pela evapotranspiração de referência (ETo). Neste sentido foram determinados os valores de Kc e ETm em estufa plástica para o meloeiro (Caron \& Heldwein, 2000; Orgaz et al., 2005), pimentão (Dalmago et al., 2003; Tazzo et al., 2004), abóbora italiana (Streck et al., 2003) e tomateiro (Dalsasso, 1997; Valandro et al., 2007); entretanto, não foram encontrados trabalhos com tal enfoque para a cultura da berinjela em ambiente protegido em clima subtropical úmido, razão pela qual se objetivou determinar a evapotranspiração máxima e os respectivos valores de coeficiente de cultura nos diferentes subperíodos de desenvolvimento da berinjela cultivada em estufa plástica.

\section{Material e Métodos}

A pesquisa foi realizada na área do Departamento de Fitotecnia da Universidade Federal de Santa Maria (UFSM), região da Depressão Central do Rio Grande do Sul (latitude: $29^{\circ} 42^{\prime} \mathrm{S}$, longitude: $53^{\circ} 48^{\prime} \mathrm{W}$ e altitude: $95 \mathrm{~m}$ ). Segundo a classificação de Köppen, o clima da região é do tipo Cfa, subtropical úmido com verões quentes, sem estação seca definida (Heldwein et al., 2009). O solo é classificado como Argissolo Vermelho distrófico arênico (EMBRAPA, 2006).

Os três experimentos foram conduzidos em estufa plástica sendo dois durante a primavera (2006 e 2007) e o terceiro durante o outono (2007). A estufa plástica, do tipo "arco pampeano", tinha $24 \mathrm{~m}$ de comprimento orientado no sentido Norte-Sul, $10 \mathrm{~m}$ de largura e $2 \mathrm{~m}$ de pé-direito lateral, totalmente recoberta com filme de polietileno de baixa densidade (PEBD) de $150 \mu \mathrm{m}$ de espessura, com cortinas laterais e uma porta em cada extremidade. Todos os dias as cortinas e as portas eram abertas próximo às $07 \mathrm{~h} 30$ para ventilação e fechadas por volta das $17 \mathrm{~h}$, ao entardecer, com exceção dos dias com previsão de geada, em que a estufa era fechada às $14 \mathrm{~h}$. Em condições de chuva e/ou vento forte, a estufa era fechada durante todo o dia para evitar danos mecânicos no filme de PEBD, sobretudo em dias de vento norte, pois este tem alta velocidade e temperatura. Por apresentarem alta tendência a erros, as determinações dos dias de vento norte foram excluídas da análise de tendência de Kc.

O preparo do solo da estufa foi feito com enxada-rotativa incorporando-se a adubação de NPK, simultaneamente. Foram construídos camalhões de solo de 0,3 m de largura e 0,2 m de altura no espaçamento de $1,0 \mathrm{~m}$, recobertos por mulching de PEBD preto opaco de $30 \mu \mathrm{m}$ de espessura, utilizado para restringir as plantas daninhas e as perdas de água por evaporação na superfície do solo. Sob o mulching foi instalado um tubo gotejador, com vazão de $1,65 \mathrm{~L} \mathrm{~h}^{-1}$, utilizado para irrigação das plantas nas fileiras, consideradas bordadura.

As mudas de berinjela (cv. Napoli) foram transplantadas no estágio de duas folhas nas datas de 15/09/2006 (primavera), 18/03/2007 (outono) e 18/10/2007 (primavera). O espaçamento entre plantas nas fileiras foi de $0,5 \mathrm{~m}$; as plantas foram conduzidas em apenas duas hastes sustentadas com fio de ráfia.

A ETm foi medida diariamente em seis repetições de evapotranspirômetros de drenagem, com volume de $20 \mathrm{~L}$ cada uma contendo substrato comercial Plantmax ${ }^{\oplus}$ e uma planta de berinjela, distribuídos de forma casualizada entre as demais plantas cultivadas no solo, que serviram de bordadura. Para determinação da ETm foi quantificada a água das irrigações do dia descontando-se a água drenada e assumindo o valor da subtração como a quantidade de água consumida pela planta e perdida predominantemente por transpiração. A nutrição das plantas dos evapotranspirômetros foi feita por fertigações semanais (Andriolo, 1996).

Realizaram-se determinações fenométricas semanais, tais como altura das plantas e dimensão linear do limbo foliar no sentido transversal, sendo seus valores usados na obtenção da área foliar de cada planta e posteriormente do índice de área foliar (IAF). As determinações fenológicas constaram das observações da data média de abertura da primeira flor e do início da colheita. Foram caracterizados os subperíodos transplante - início da antese (T-IA), início da antese - início da colheita (IA-IC) e início da colheita - final da colheita (IC-FC).

Os valores diários de ETo foram calculados por meio do método de Penman-Monteith (Allen et al., 1998), utilizando-se os dados da estação meteorológica automática do INMET em Santa Maria, distante cerca de $130 \mathrm{~m}$ da estufa plástica. Pela razão entre o valor medido de ETm e a ETo calculada foram obtidos o Kc diário da berinjela e seu valor médio para os três subperíodos.

Estabeleceram-se regressões lineares e não-lineares entre as variáveis Kc e IAF, Kc e DAT, ETm e IAF e ETm e DAT pelo método dos quadrados mínimos para verificar a 
interdependência entre essas variáveis. Determinaram-se valores médios e desvio padrão de ETm e Kc para os diversos subperíodos (T-IA, IA-IC e IC-FC) nos diferentes experimentos.

\section{Resultados e Discussão}

Os resultados dos três experimentos apresentam diferenças entre si para a duração dos subperíodos e para as curvas do IAF e da ETm da cultura (Figura 1). O início da antese (IA) ocorreu aos 46; 43 e 51 DAT enquanto o IC foi observado aos 74; 86 e 81 DAT, respectivamente, para os experimentos de primavera de 2006, outono de 2007 e primavera de 2007. A ETm diária da berinjela apresentou relação com o IAF com tendência de crescimento em função dos DAT ao longo do período experimental; entretanto, esta tendência se apresenta diferente para cada experimento, sobremaneira do outono em relação à primavera, pois no outono tende a decrescer após a antese (Figura 1).
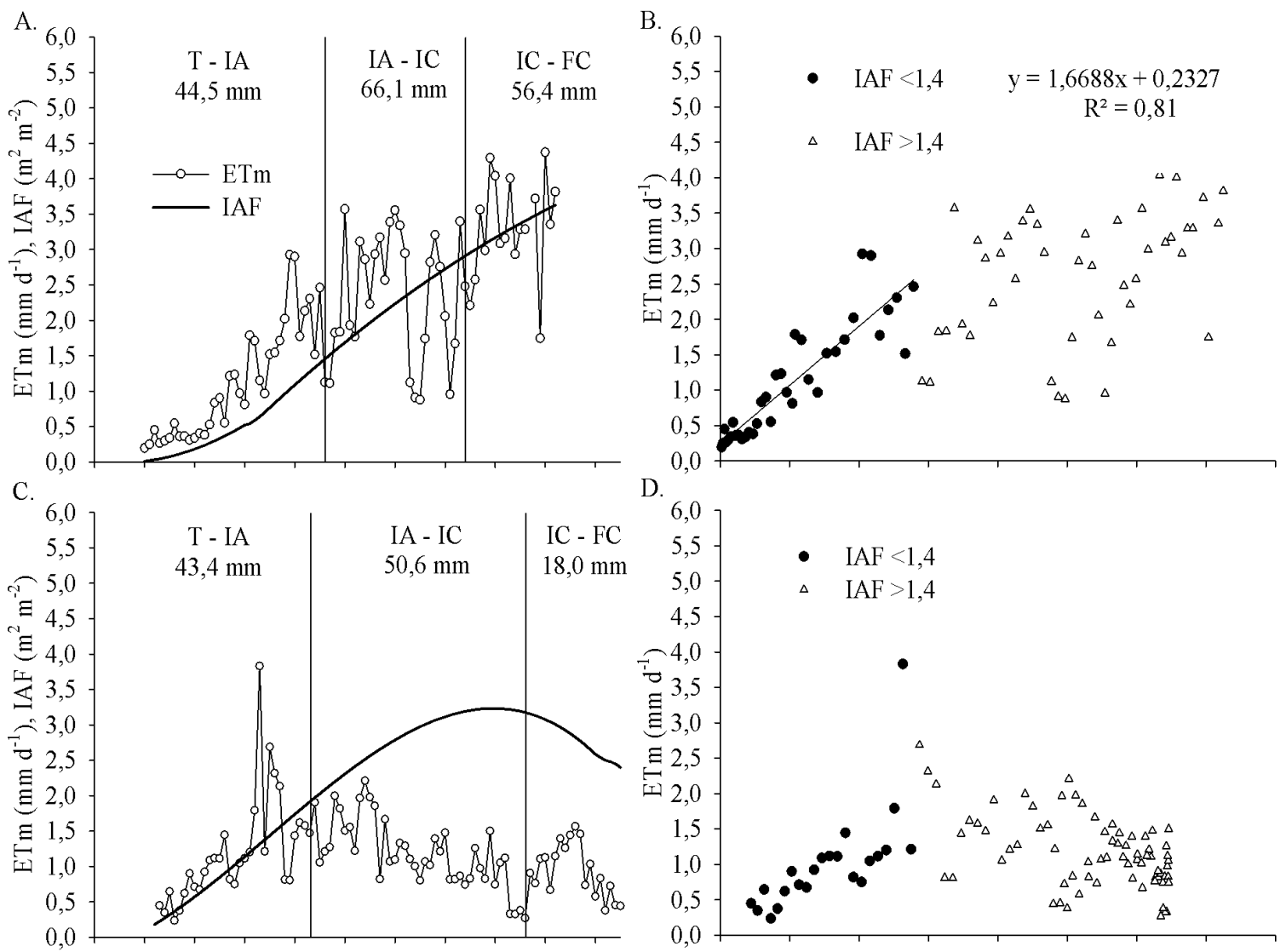

D.
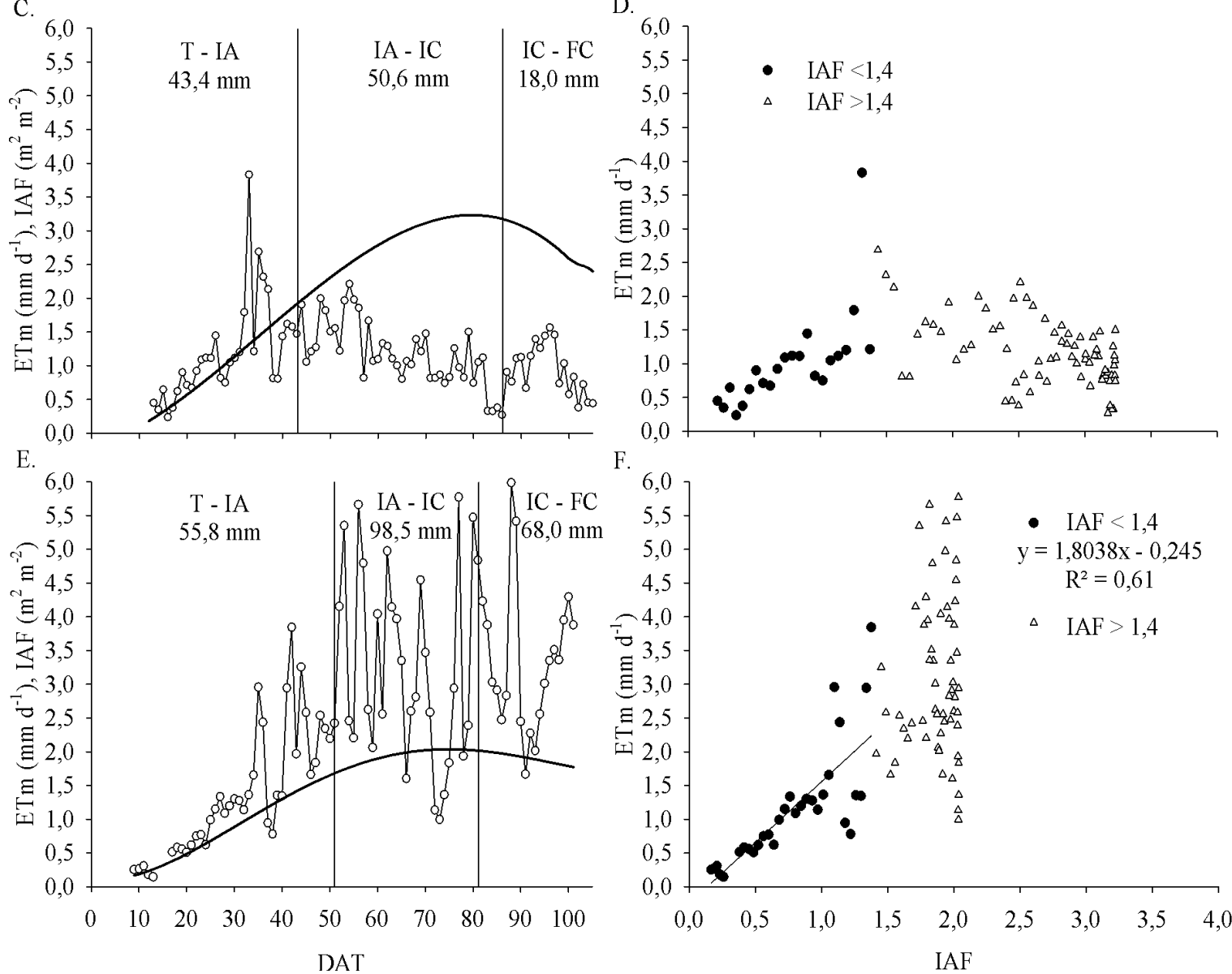

As siglas T-IA, IA-IC, IC-FC representam os subperíodos transplante (T) ao início da antese (IA), IA ao início da colheita (IC) e IC ao seu final (FC), respectivamente

Figura 1. Evapotranspiração máxima (ETm) diária e acumulada por subperíodos e índice de área foliar (IAF) da berinjela cultivada em estufa plástica em função do número de dias após o transplante (DAT) $(A, C, E)$ e ETm em função do índice de área foliar (IAF $\leq 1,4$ e IAF > 1,4) (B, D, F); na primavera de 2006 (A, B) e de 2007 (E, F) e outono de 2007 (C, D) 
No primeiro experimento o IAF alcançou o valor máximo de $3,63 \mathrm{~m}^{2} \mathrm{~m}^{-2}$, e um valor máximo de evapotranspiração de $4,37 \mathrm{~mm} \mathrm{~d}^{-1}$ no final do ciclo (Figura $1 \mathrm{~A}$ ). O ciclo teve duração de 92 dias com ETm média de $1,82 \mathrm{~mm} \mathrm{~d}^{-1}$ e ETm acumulada de $167 \mathrm{~mm}$. A maior ETm média diária ocorreu no subperíodo IC-FC, embora o maior consumo de água acumulado tenha ocorrido no subperíodo IA-IC. A tendência de aumento da ETm ocorreu em seguida ao incremento do IAF, sobretudo dos 20 aos 60 DAT e ao aumento da demanda atmosférica no decorrer do ciclo embora a ETm apresentasse grande oscilação entre os dias mormente devido às variações dos elementos meteorológicos (Figura 2).

No experimento de outono de 2007 verificou-se tendência de aumento da ETm até os 35 DAT, com valor máximo de $3,80 \mathrm{~mm} \mathrm{~d}^{-1} \mathrm{e}$ após tendência de decréscimo até o final do ciclo (Figura 1C). Referida tendência é distinta daquela da primavera em 2006 e 2007, evento justificado em virtude da época de cultivo ter sido a do outono, em que a demanda atmosférica diminui gradativamente no final do ciclo em função das condições meteorológicas (Figura 2).

A ETm acumulada no ciclo de outono de 2007 (105 dias) foi de $112 \mathrm{~mm}$, sendo a média diária $1,07 \mathrm{~mm} \mathrm{~d}^{-1}$ e o IAF máximo de $3,23 \mathrm{~m}^{2} \mathrm{~m}^{-2}$ aos $78 \mathrm{DAT}$. A ocorrência da máxima ETm diária cerca de 35 dias antes do IAF máximo demonstra que no outono o padrão de necessidade de irrigação da berinjela em estufa não é o mesmo que na primavera.

Na primavera de 2007 verificou-se maior ETm diária a partir dos 35 DAT em relação aos outros dois experimentos. Mesmo com um IAF máximo de $2,02 \mathrm{~m}^{2} \mathrm{~m}^{-2}$, menor que $63 \%$ do IAF máximo dos experimentos anteriores, a ETm atingiu o valor máximo de $5,96 \mathrm{~mm} \mathrm{~d}^{-1}$ aos 88 DAT (Figura 1E). A maior ETm acumulada ocorreu no subperíodo IA-IC com 98,5 mm enquanto o valor total evapotranspirado foi de 222,3 $\mathrm{mm}$ no ciclo de 102 dias sendo a média de $2,18 \mathrm{~mm} \mathrm{~d}^{-1}$. Este alto consumo de água, principalmente em relação ao experimento de outono, pode ser explicado pelo fato deste experimento coincidir com um período de maior densidade de fluxo de radiação solar incidente e de alta temperatura e déficit de saturação do ar (Figura 2A, 2B e 2C), resultando em uma alta demanda atmosférica quando as plantas já apresentavam IAF próximo do máximo.

A tendência do incremento do IAF e do aumento gradativo da demanda atmosférica e do consumo de água durante a primavera (Figuras 1A e 1E), também foi observada em cultivos protegidos primaveris de tomate (Dalsasso et al., 1997) e melão (Caron \& Heldwein, 2000) época em que a radiação solar, o saldo de radiação, a temperatura e o déficit de saturação de vapor do ar apresentam valores crescentes (Figura 2), o que permite inferir serem os elementos meteorológicos que mais afetam a tendência da ETm diária no ciclo, além da variação aperiódica tal como já comprovado por Nerderhoff et al. (1992) e Dalmago et al. (2006) para o pimentão.

O experimento de outono (Figura 1C) apresentou menor consumo de água em relação aos experimentos de primavera,

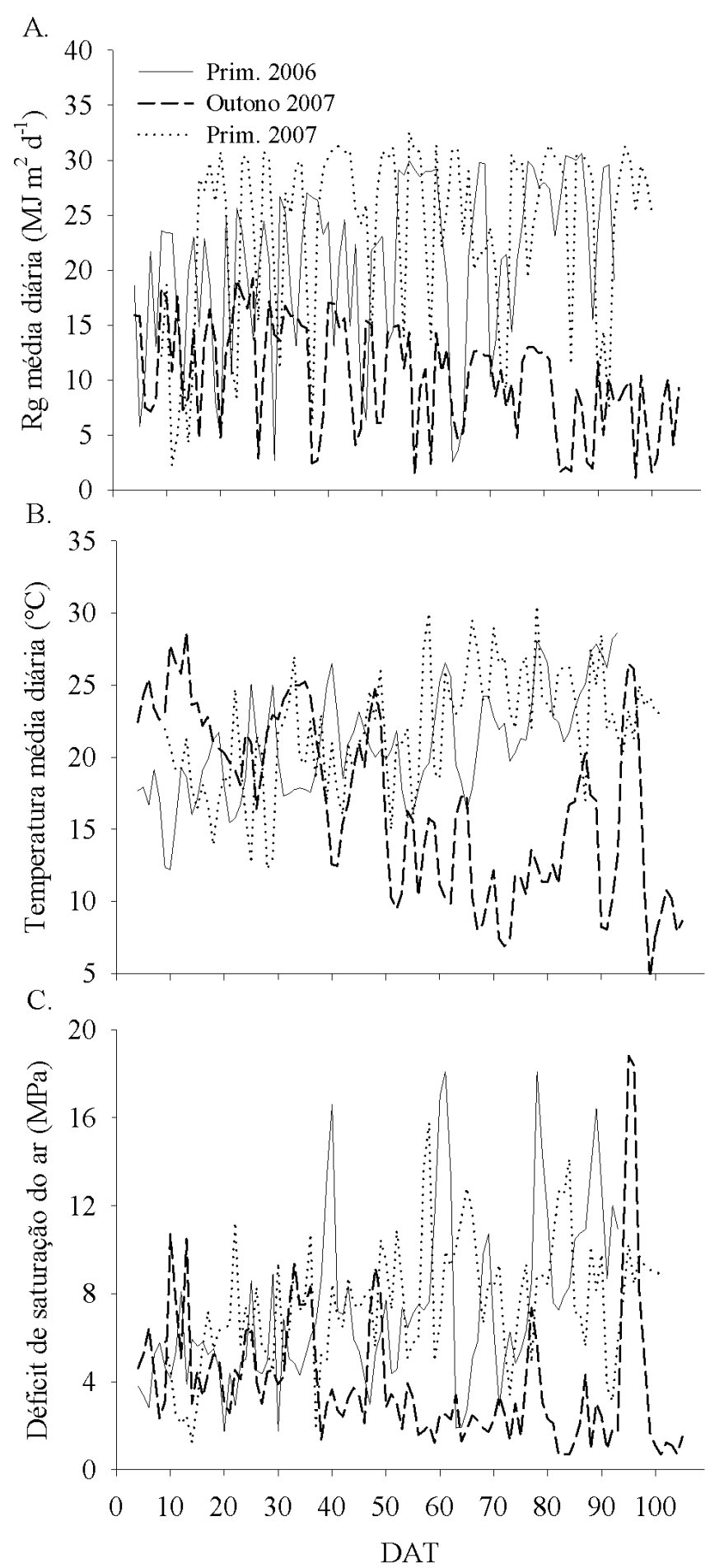

Figura 2. Média diária da radiação solar global (A), temperatura do ar (B) e déficit de saturação do ar (C) em dias após o transplante (DAT) da berinjela cultivada em estufa plástica no outono de 2007 e nas primaveras de 2006 e 2007

principalmente após os 40 DAT. Este resultado está em concordância com o obtido para o tomateiro cultivado sob estufa plástica cujo consumo de água das plantas foi mais elevado na primavera do que no outono (Dalsasso et al., 1997; Valandro et al., 2007), sobretudo porque a demanda atmosférica diminui muito nos subperíodos mais avançados 
dos cultivos de outono, nos quais a planta demandaria mais água devido ao maior IAF.

A ETm da berinjela apresenta relação com o IAF crescente (Figura 1), obtendo-se altos coeficientes de determinação para o período inicial de desenvolvimento em que o IAF ainda se apresentava menor que 1,4 (Figuras 1B, 1D e 1F). Com o crescimento das plantas e o aumento do IAF tendendo à cobertura da superfície pelo dossel, a ETm diária apresenta maior variabilidade sendo mais afetada pelas condições meteorológicas, não ocorrendo uma associação clara com o IAF. Desta forma, apenas para o período inicial de desenvolvimento da berinjela seria possível estimar a tendência da ETm diária a partir do IAF com razoável precisão.

Nos cultivos de primavera de 2006 e 2007 (Figura 1B e 1F) foram obtidos, enquanto não foi alcançado IAF maior do que 1,4 , coeficientes de determinação $\left(\mathrm{R}^{2}\right)$ de 0,81 e 0,61 , respectivamente, porém não houve boa correlação quando IAF $>$ 1,4. Em pimentão cultivado na mesma época em estufa plástica Dalmago et al. (2003) encontraram resultados semelhantes, sendo o coeficiente de determinação do modelo para IAF $\leq$ 1,4 igual a 0,85 , e também não houve boa determinação para IAF $>1,4$.

O cultivo de outono (Figura 1D) apresentou tendência de aumento da ETm até IAF de 1,4 seguindo a tendência de um pequeno decréscimo, mesmo para IAF maiores. O mesmo

comportamento foi observado para cultivo de abóbora italiana no outono (Streck et al., 2003), o que confirma ser a diminuição da demanda atmosférica determinante para o decréscimo da ETm mesmo com incremento do IAF, à medida em que se ultrapassa o equinócio de outono e se aproxima o solstício de inverno e o dossel já apresenta IAF $>1,4$. Os resultados dos três experimentos (Figura 1) permitem inferir que nos períodos do ciclo em que o IAF é maior que cerca de $1,4 \mathrm{~m}^{2} \mathrm{~m}^{-2}$, o que representa cobertura foliar sobre a maior parte da superfície, as diferenças de ETm entre os dias são mais dependentes da variação das condições meteorológicas do que do IAF.

Os valores de Kc apresentaram relação com o DAT e com o IAF ao longo do ciclo da cultura (Figura 3). Para ambas as épocas de cultivo a relação entre o Kc e o DAT foi sigmoidal, mesma tendência encontrada para o pimentão (Dalmago et al., 2003). Obteve-se um valor pequeno de Kc nos primeiros DAT tendendo a um crescimento quase exponencial dos 20 aos 40 DAT e estabilização posterior (Figuras 3A e 3C). Os valores de Kc médio para a primavera apresentaram uma linha de tendência com um valor máximo em torno de 0,69 (Figura $3 \mathrm{~A}$ ). Por sua vez, para a época do outono os valores de Kc foram maiores do que na primavera resultando em uma elevação maior da curva alcançando o maior valor médio de 1,19 ao alcançar IAF máximo (Figura 3C).
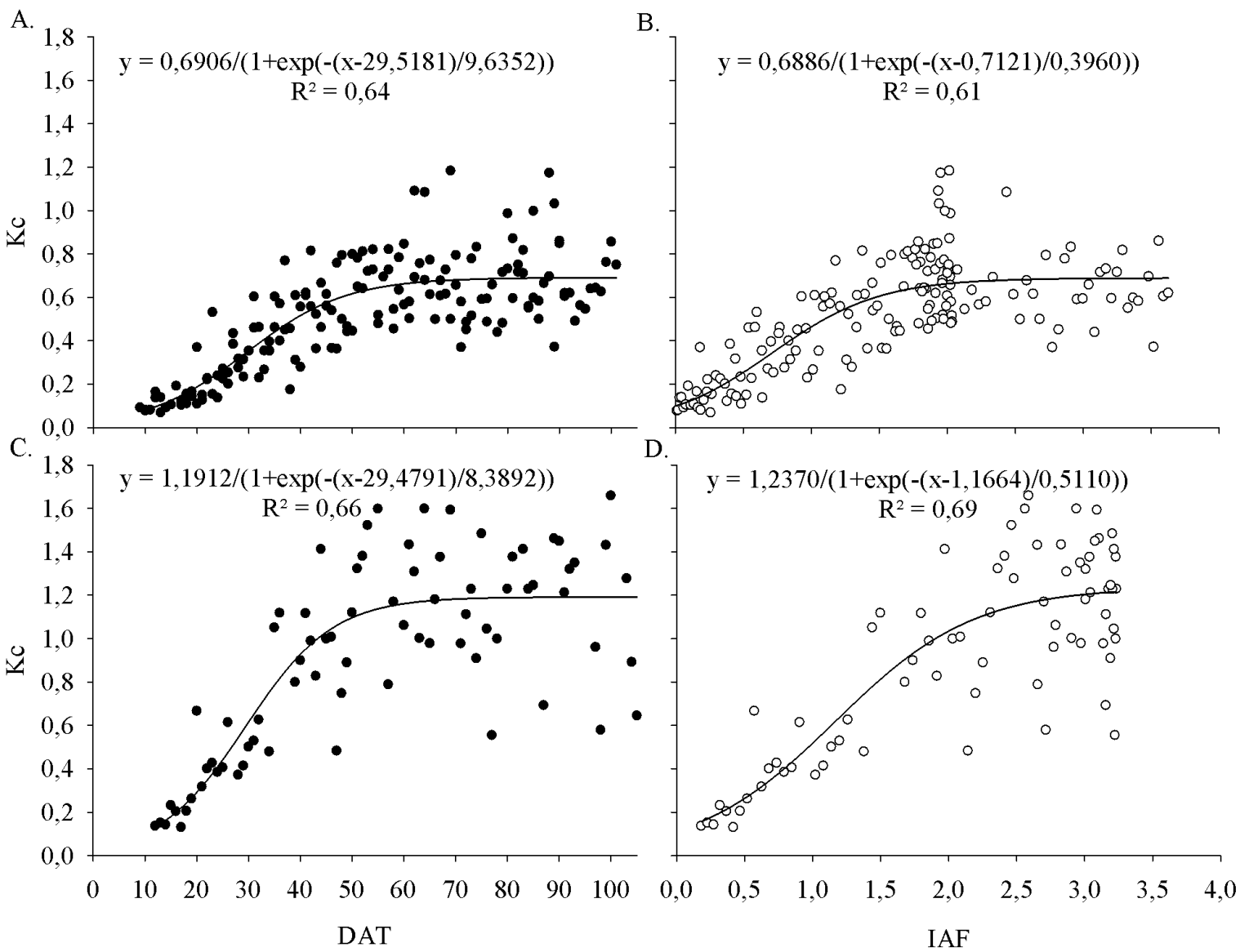

Figura 3. Coeficiente de cultura (KC) da berinjela cultivada em estufa plástica na primavera (A, B) e no outono (C, D) em função dos dias após o transplante (DAT) e do índice de área foliar (IAF) 
Tabela 1. Coeficiente de cultura (Kc) máximo (Máx), mínimo (Mín) e médio (Méd) com desvio padrão, da berinjela em cultivos de primavera (Prim.) e outono sob estufa plástica, em diferentes subperíodos de desenvolvimento

\begin{tabular}{|c|c|c|c|c|c|c|c|c|c|c|}
\hline \multirow{2}{*}{ Subperíodo* } & \multicolumn{3}{|c|}{ Kc - Prim. 2006} & \multicolumn{3}{|c|}{ Kc - Prim. 2007} & Kc - Prim. & \multicolumn{3}{|c|}{ Kc - Outono 2007} \\
\hline & Méd & Máx & Mín & Méd & Máx & Mín & Méd & Méd & Máx & Mín \\
\hline T-IA & $0,31 \pm 0,17$ & 0,62 & 0,08 & $0,36 \pm 0,21$ & 0,81 & 0,07 & $0,34 \pm 0,19$ & $0,47 \pm 0,31$ & 1,12 & 0,13 \\
\hline IA-IC & $0,65 \pm 0,15$ & 1,08 & 0,37 & $0,71 \pm 0,20$ & 1,18 & 0,46 & $0,67 \pm 0,17$ & $1,16 \pm 0,28$ & 1,60 & 0,48 \\
\hline IC-FC & $0,64 \pm 0,13$ & 0,86 & 0,37 & $0,72 \pm 0,18$ & 1,17 & 0,49 & $0,69 \pm 0,17$ & $1,19 \pm 0,34$ & 1,66 & 0,58 \\
\hline
\end{tabular}

*Subperíodos: transplante ao início da antese (T-IA); início da antese ao início da colheita (IA-IC); início ao final da colheita (IC-FC)

A demanda atmosférica é menor nos cultivos de outono do que primavera e a ETm da cultura também é menor nessa época do ano (Dalsasso et al., 1997; Valandro et al., 2007). Entretanto, a relação $\mathrm{ETm} \mathrm{ETo}^{-1}$, que resulta no Kc, é maior no outono do que na primavera, o que também foi verificado para tomateiro e pepineiro, por Dalsasso (1997). Este resultado pode ser explicado pelo fato de que a ETo foi calculada para condições de ambiente externo da estufa enquanto a ETm foi medida dentro da estufa. O ganho de energia dentro da estufa no outono é bastante elevado em comparação com ambiente externo, com temperatura do ar e déficit de saturação internos superiores (Righi et al., 2002; Vázques et al., 2005), pelo menos durante o período de aquecimento diário (Buriol et al., 1997). Tal condição decorre, provavelmente, do maior aquecimento do ar durante sua passagem contínua na direção transversal pela estufa em função da direção predominante do vento em Santa Maria (E, ESE e SE), o que pode resultar em uma ETm maior em relação a ETo aumentando os valores de Kc.

As relações entre o Kc e IAF também foram representadas por equações sigmoidais (Figuras 3B e 3D). Valores baixos de Kc foram verificados quando o IAF ainda era pequeno, nos primeiros DAT. Constata-se haver tendência de aumento do Kc com o aumento do IAF e uma tendência posterior de estabilização, em ambas as épocas de cultivo.

As equações apresentadas na Figura 3 podem ser utilizadas para estimativa do Kc. Salienta-se que a utilização das equações originárias dos dados de DAT poderia ser a mais indicada do ponto de vista da maior facilidade de obtenção da variável DAT do que IAF, pois apresentam coeficientes de determinação semelhantes às equações obtidas a partir do IAF. No entanto, os coeficientes de determinação do IAF e DAT foram semelhantes nos respectivos períodos experimentais. As equações das Figuras $3 \mathrm{~A}$ e $3 \mathrm{~B}$ podem ser utilizadas para cálculo do Kc para a primavera enquanto as equações das Figuras $3 \mathrm{C}$ e 3D são indicadas para a estimativa dos valores diários do Kc para cultivos de berinjela no outono em estufa plástica em Santa Maria, RS.

Os valores médios e extremos de Kc nos diferentes subperíodos foram menores no subperíodo T-IA (Tabela 1), tanto na primavera quanto no outono. Para Streck et al. (2003) este resultado é devido aos baixos valores iniciais de IAF da cultura e consequente menor ETm, além do efeito da cobertura da superfície do solo com mulching plástico preto que restringe a evaporação na superfície do solo (Xie et al., 2005; Dalmago et al., 2006).

Na média, os maiores valores de Kc foram observados para o subperíodo IC-FC e IA-IC, respectivamente na primavera e no outono, sendo que no experimento de outono ocorreram os maiores valores de Kc médio, máximo e mínimo em comparação com a média de primavera (Tabela 1 ). O Kc médio da berinjela cultivada na primavera foi de 0,51 enquanto o de outono foi de 0,89 , sendo de 0,70 a média geral. Conforme Reis et al. (2009), o Kc médio para tomate caqui cultivado em estufa plástica foi de 0,65 , valor muito próximo ao obtido para a berinjela.

$\mathrm{Na}$ literatura foram encontrados resultados similares para outras culturas olerícolas cultivadas em estufa plástica na primavera e no outono. Cultivando meloeiro na primavera, Caron \& Heldwein (2000) encontraram valores de 0,34; 0,71 e 0,75 , respectivamente para os subperíodos: T-IA, IA-IC e ICFC. Em cultivos de outono, Streck et al. (2003) encontraram valores de Kc médios para abóbora italiana de 0,5 e 1,12 para os subperíodos transplante-início da frutificação e início da frutificação-final da colheita, respectivamente, enquanto Dalmago et al. (2003) determinaram os valores de Kc médios do pimentão de 0,66 e 1,06 respectivamente para os subperíodos IA-IC e IC-FC.

Os resultados obtidos para berinjela podem ser considerados representativos para as condições de clima subtropical úmido em que foram obtidos. Para a estimativa da ETm de cultivos de berinjela em estufa plástica devem ser utilizados os valores de Kc específicos para a primavera e para o outono, respectivamente (Tabela 1 e Figura 3).

\section{Conclusões}

1. A evapotranspiração acumulada da berinjela cultivada em estufa plástica é maior na primavera do que no outono, em Santa Maria, RS.

2. O coeficiente de cultura da berinjela cultivada em estufa plástica pode ser estimado com precisão aceitável a partir dos dias após o transplante (DAT) e índice de área foliar (IAF), tanto para cultivos de primavera quanto para cultivos de outono.

3. Os valores médios de coeficiente de cultura da berinjela para os subperíodos transplante-início da antese, início da antese-início de colheita e início de colheita-final de colheita são, respectivamente, de 0,34; 0,67 e 0,69 para a primavera, e de 0,$47 ; 1,16$ e 1,19 para o outono.

\section{Agradecimentos}

Os autores agradecem ao CNPq, à CAPES e à FAPERGS, pelos respectivos auxílios na forma de bolsas de pesquisa/estudo recebidas durante a realização deste trabalho. 


\section{Literatura Citada}

Allen, R. G.; Pereira, L. S.; Raes, D.; Smith, M. Crop evapotranspiration-Guidelines for computing crop water requirements-FAO Irrigation and drainage paper 56 . Rome: FAO, 1998. 301p.

Andriolo, J. L. O cultivo de plantas com fertirrigação. Santa Maria: UFSM, 1996. 47p.

Antonini, A. C.; Robles, W. G. R.; Tessarioli Neto, J.; Kluge, R. A. Capacidade produtiva de cultivares de berinjela. Horticultura Brasileira, v.20, p.646-648, 2002.

Bilibio, C.; Carvalho, J. D. A.; Martins, M.; Rezende, F. C.; Freitas, E. A.; Gomes, L. A. Desenvolvimento vegetativo e produtivo da berinjela submetida a diferentes tensões de água no solo. Revista Brasileira de Engenharia Agrícola e Ambiental, v.14, p.730-735, 2010.

Buriol, G. A.; Heldwein, A. B.; Schneider, F. M.; Estefanel, V.; Gazola, M. Ganho térmico devido a estufa plástica em Santa Maria, RS. Revista Brasileira de Agrometeorologia, v.12, p.43-49, 2004.

Buriol, G. A.; Luft, S. V. L.; Heldwein, A. B.; Streck, N. A.; Schneider, F. M. Efeito da ventilação sobre a temperatura e umidade do ar em túneis baixos de polietileno transparente eo crescimento da alface. Revista Brasileira de Agrometeorologia, v.5, p.17-24, 1997.

Caron, B. O.; Heldwein, A. B. Consumo d'água e coeficiente de cultura para o meloeiro cultivado em estufa plástica na primavera. Revista Brasileira de Agrometeorologia, v.8, p.19-25, 2000.

Dalmago, G. A.; Heldwein, A. B.; Buriol, G. A.; Luzza, J.; Tazzo, I. F.; Trentin, G. Evapotranspiração máxima e coeficiente da cultura do pimentão em estufa plástica. Revista Brasileira de Agrometeorologia, v.11, p.33-41, 2003.

Dalmago, G. A.; Heldwein, A. B.; Nied, A. H.; Grimm, E. L.; Pivetta, C. R. Evapotranspiração máxima da cultura de pimentão em estufa plástica em função da radiação solar, da temperatura, da umidade relativa e do déficit de saturação do ar. Ciência Rural, v.36, p.785-792, 2006.

Dalsasso, L. C. M. Consumo d'água e coeficiente de cultura do tomateiro (Lycopersicum esculentum, M.) e do pepino (Cucumis sativus, L.) cultivados em estufa plástica. Santa Maria: UFSM. 1997. 84p. Dissertação Mestrado

Dalsasso, L. C. M.; Heldwein, A. B.; Buriol, G. A. Consumo d'água do tomateiro tipo salada em estufa plástica. Revista Brasileira de Agrometeorologia, v.5, p.61-67, 1997.

EMBRAPA - Empresa Brasileira de Pesquisa Agropecuária. Centro Nacional e Pesquisa em Solos. Sistema Brasileiro de Classificação de Solos. Brasília: Embrapa SPI; Rio de Janeiro: Embrapa Solos, 2006. 306p.

Fernández, M. D.; Bonachela, S.; Orgaz, F.; Thompson, R.; López, J. C.; Granados, M. R.; Gallardo, M.; Fereres, E. Measurement and estimation of plastic greenhouse reference evapotranspiration in a Mediterranean climate. Irrigation Science, v.28, p.497-509, 2010.
Ferreira, R. L. F.; Negreiros, M. Z. de.; Leitão, M. M. V. B. R.; Araujo Neto, S. E. de.; Araujo, A. de. P.; Sousa, J. W. de. Influência da cobertura do solo na produção do meloeiro. Revista de Ciências Agrárias, v.46, p.215-226, 2006.

Gonçalves, M. da C. R.; Diniz, M. F. M.; Henriques, A.; Dantas, J. D. C. B. Modesto efeito hipolipemiante do extrato seco de berinjela (Solanum melongena L.) em mulheres com dislipidemias, sob controle nutricional. Revista Brasileira de Farmacognosia, v.16, p.656-663, 2006.

Heldwein, A. B.; Buriol, G. A.; Streck, N. A. O clima de Santa Maria. Ciência \& Ambiente, v.38, p.43-58, 2009.

Heldwein, A. B.; Streck, L.; Schneider, F. M.; Grimm, E. L.; Nied, A. H.; Tazzo, I. F. Modelos para a estimativa da evapotranspiração máxima da abóbora italiana em estufa plástica. Revista Brasileira de Agrometeorologia, v.12, p.75-86, 2004.

Karam, F.; Saliba, R.; Skaf, S.; Breidy, J.; Rouphael, Y.; Balendonck, $\mathrm{J}$. Yield and water use of eggplants (Solanum melongena L.) under full and deficit irrigation regimes. Agricultural Water Management, v.98, p.1307-1316, 2011.

Nerderhoff, E. M.; Rijsdijk, A. A.; De Graaf, R. Leaf conductance and rate of crop transpiration of greenhouse grown sweet pepper (Capsicum annuum L.) as affected by carbon dioxide. Scientia Horticulturae, v.52, p.283-301, 1992.

Orgaz, F.; Fernández, M. D.; Bonachela, S.; Gallardo, M.; Fereres, E. Evapotranspiration of horticultural crops in an unheated plastic greenhouse. Agricultural Water Management, v.72, p.81-96, 2005.

Pivetta, C. R.; Heldwein, A. B.; Maldaner, I. C.; Radons, S. R.; Tazzo, I. F.; Lucas, D. D. P. Evapotranspiração máxima do tomateiro cultivado em estufa plástica em função de variáveis fenométricas e meteorológicas. Bragantia, v.70, p.707-714, 2011.

Reis, L. S.; Souza, J. D.; Azevedo, C. D. Evapotranspiração e coeficiente de cultivo do tomate caqui cultivado em ambiente protegido. Revista Brasileira de Engenharia Agrícola e Ambiental, v.13, p.289-296, 2009.

Ribeiro, C. S. C. Berinjela (Solanum melongena L.). Embrapa Hortaliças, Sistemas de Produção, 3, Versão Eletrônica Nov/2007 <http://sistemasdeproducao.cnptia.embrapa. br/FontesHTML/Beringela/Beringela_Solanum_ melongena_L/index.html> 22 Fev. 2012.

Righi, E. Z.; Angelocci, L. R.; Buriol, G. A.; Heldwein, A. B. Transpiração do tomateiro cultivado em estufa plástica e suas relações com a radiação solar e déficit de saturação do ar. Revista Brasileira de Agrometeorologia, v.10, p.9-18, 2002.

Streck, L.; Heldwein, A. B.; Buriol, G. A.; Dalmago, G. A.; Trentin, G.; Wilsmann, S. Evapotranspiração máxima e coeficiente de cultura da abóbora italiana em estufa plástica. Revista Brasileira de Agrometeorologia, v.11, p.43-52, 2003. 
Tazzo, I. F.; Heldwein, A. B.; Grimm, E. L.; Maass, G. F.; Pivetta, C. R. Evapotranspiração máxima e coeficiente de cultura para o pimentão cultivado em estufa plástica na primavera. Revista Brasileira de Agrometeorologia, v.12, p.275-281, 2004.

Tazzo, I. F.; Heldwein, A. B.; Maldaner, I. C.; Pivetta, C. R.; Streck, L.; Righi, E. Z. Evapotranspiração do pimentão em estufa plástica estimada com dados meteorológicos externos, na primavera. Revista Brasileira de Engenharia Agrícola e Ambiental, v.16, p.269-274, 2012.
Valandro, J.; Andriolo, J. L.; Buriol, G. A.; Heldwein, A. B. Transpiração do tomateiro cultivado fora do solo em estufa plástica e sua relação com os elementos meteorológicos. Ciência Rural, v.37, p.1593-1600, 2007.

Vásquez, M. A. N.; Folegatti, M. V.; Dias, N. da S.; Silva, C. R. Efeito do ambiente protegido cultivado com melão sobre os elementos meteorológicos e sua relação com as condições externas. Engenharia Agrícola, v.25, p.137-143, 2005.

Xie, Z. K.; Wang, Y. J.; Li, F. M. Effect of plastic mulching on soil water use and spring wheat yeld in arid region of northwest China. Agricultural Water Manegement, v.75, p.71-83, 2005. 